\title{
Evidence for a Role of Progesterone in Menstrual Cycle-Related Variability in Prepulse Inhibition in Healthy Young Women
}

\author{
Veena Kumari*, 1,2, Joanna Konstantinou', Andrew Papadopoulos ${ }^{3}$, Ingrid Aasen', Lucia Poon ${ }^{3}$, \\ Rozmin Halari' and Anthony J Cleare ${ }^{3,4}$ \\ 'Department of Psychology, Institute of Psychiatry, King's College London, London, UK: ${ }^{2}$ NIHR Biomedical Research Centre for Mental Health \\ at the Institute of Psychiatry and South London and Maudsley NHS Trust, London, UK; ${ }^{3}$ Affective Disorder Unit, Bethlem Royal Hospital, \\ Beckenham, Kent, UK; ${ }^{4}$ Division of Psychological Medicine and Psychiatry, Institute of Psychiatry, King's College London, London, UK
}

Prepulse inhibition (PPI) of the startle response is sensitive to sex, with healthy young women showing less PPI compared with age-matched men, and varies according to the menstrual cycle phase in women. Relatively less is known regarding sex and hormonal influences in prepulse facilitation (PPF). Menstrual phase-related variability in PPI is suggested to be mediated by fluctuating estrogen level, based on the observations of more PPI in women during the follicular, relative to the luteal, phase. No study has directly assessed the relationship between fluctuating hormones and PPI or PPF levels over the human ovarian cycle. To examine the roles of circulating ovarian hormones in PPI and PPF, 16 non-smoking regularly menstruating healthy women were tested during both the follicular and luteal phases on PPI and PPF and provided saliva samples for measurement of $17 \beta$-estradiol (estrogen), progesterone and testosterone. The results showed higher levels of $17 \beta$-estradiol and progesterone during the luteal, relative to the follicular, phase; and more PPI during the follicular phase and more PPF during the luteal phase with comparable startle amplitude and habituation during the two phases. A larger increase in progesterone was associated with a smaller decrease in PPI from the follicular to the luteal phase. No significant associations were found between changes in PPI/PPF and estrogen levels. The findings confirm lower PPI during the luteal, compared with the follicular, phase and suggest a role for progesterone, more specifically an antipsychotic-like PPI-restoration action of progesterone, during the luteal phase in PPI of young women.

Neuropsychopharmacology (2010) 35, 929-937; doi:I0.1038/npp.2009.195; published online 2 December 2009

Keywords: acoustic startle; sensorimotor gating; sex difference; estrogen; follicular; luteal

\section{INTRODUCTION}

Prepulse-elicited startle modulation is increasingly used as a measure of information processing in both clinical and non-clinical populations as well as in experimental animals (for reviews, see Braff et al, 2001; Geyer et al, 2001). A reduction in amplitude of the startle response when the startling stimulus is preceded by a weak prepulse by $30-500 \mathrm{~ms}$ is known as prepulse inhibition (PPI), and a facilitation in amplitude of the startle response when the startling stimulus is preceded by a weak prepulse by $>500 \mathrm{~ms}$ is known as prepulse facilitation (PPF) (Hoffman and Searle, 1968; Graham, 1975). PPI is thought to provide an operational index of sensorimotor gating; while

*Correspondence: Professor $\vee$ Kumari, Department of Psychology, P078, Institute of Psychiatry, King's College London, De Crespigny Park, London SE5 8AF, UK, Tel: + 0044207848 0233, Fax: 0044207848 0860, E-mail: v.kumari@iop.kcl.ac.uk

Received 13 August 2009; revised 6 October 2009; accepted 29 October 2009 resources are targeted at the prepulse, any incoming information (ie, the pulse) is attended to a reduced level thereby protecting the processing of the initial stimulus (Graham and Murray, 1977). A reduced ability to avoid such stimulus interference may cause sensory over-stimulation and confusion (Braff and Geyer, 1990), as observed, for example, in people with schizophrenia who also show impaired PPI (eg, Braff et al, 1978, 2001; Swerdlow et al, 2006). PPF may reflect sustained attention (Dawson et al, 1997), or sensory enhancement linked with modalityspecific selective attention (Anthony, 1985). PPF is a relatively less studied phenomenon.

PPI shows sensitivity to sex in healthy populations with several studies reporting less PPI in young women, when tested regardless of where they are in their menstrual cycle, than young men (Swerdlow et al, 1993, 1997, 1999; Abel et al, 1998; Kumari et al, 2003, 2004, 2008; Aasen et al, 2005). A sex effect in PPI (women less than men) has also been reported in rats (Koch, 1998; Faraday et al, 1999) and mice (Ison and Allen, 2007). Furthermore, PPI is sensitive to 
menstrual cycle status in healthy women, with more PPI observed during the follicular phase relative to the luteal phase in both cross-sectional (Swerdlow et al, 1997) and within-subjects investigations (Jovanovic et al, 2004). Sex differences in PPF are less widely studied. Previous studies from our laboratory suggest that women show higher PPF than men (Kumari et al, 2003; Aasen et al, 2005). There is no published research to our knowledge examining menstrual cycle-related variability in PPF.

In healthy women, lower PPI during the luteal, compared with the follicular, phase is considered to be caused by high levels of the ovarian hormone, estrogen, during the luteal phase (Jovanovic et al, 2004). However, a recent study (Talledo et al, 2009) found no direct relationship between PPI and estrogen levels in healthy women. Furthermore, within schizophrenia populations, a later age of illness onset, less severe forms of schizophrenia, superior response to antipsychotics, and better functional and social outcomes are reported for women than men with schizophrenia (Castle and Murray, 1991; Faraone et al, 1994; Castle et al, 1995), supposedly because of a neuroprotective role of estrogen in women (Häfner et al, 1998; Kulkarni, 2009). Female schizophrenia patients also show greater symptom severity during the periods of low estrogen (eg, postpartum) and lower symptom severity during the periods of high estrogen (eg, pregnancy, Riecher-Rössler et al, 1994). Clearly, given the relevance of PPI as an important animal model of schizophrenia, more work is needed to understand the role of estrogen in sex and menstrual cycle-related variations in PPI. There may also be a role for progesterone, another ovarian hormone, which shows marked fluctuations over the menstrual cycle (Marshall, 2001) and has been implicated in modulation of PPI in experimental animals (Rupprecht et al, 1999; Gogos and Van den Buuse, 2004). No experimental study, to our knowledge, has directly analyzed relationships between PPI/PPF and fluctuations in estrogen and progesterone over the menstrual cycle.

In this study, we examined menstrual phase-related variability in both PPI and PPF with concurrent assessment of estrogen, progesterone, and testosterone levels. We hypothesized that women would show decreased PPI during the luteal phase, relative to the follicular phase, and this decrease would be more prominent in those showing marked estrogen increases during the luteal phase. An opposite pattern of effects was expected for PPF but with limited confidence given the lack of robust previous data on that part of our investigation.

\section{MATERIALS AND METHODS}

\section{Participants and Design}

The study initially involved 24 healthy non-smoking regularly menstruating women (aged 18-40 years). Exclusion criteria included: (i) any ear disorder, (ii) lefthandedness, (iii) diagnosis of a psychiatric or neurological disorder or a current or past primary diagnosis of substance misuse (no current drug abuse confirmed with urine toxicology in a sub-sample), (iv) the use of any oral contraceptives, and (v) regular medical prescription. All included participants had 26-30 days menstrual cycle determined using the standard 'counting forward and backward' and intact auditory abilities tested using an audiometer (Kamplex, AS7) at $40 \mathrm{~dB}$ (A) $(1000 \mathrm{~Hz})$. In all, 19 of the 24 initially recruited women completed the testing on both occasions and, of these 19, 16 women (mean age $\pm 1 S D=24.0,5.48$ years) provided usable data on both occasions. Of the three excluded participants, one had a low response rate $(<70 \%$ response probability), and two participants had noisy data (unstable baselines; see Startle Response Measurement) on at least one occasion of testing. Of those 16 women who provided usable data on both occasions, luteal $17 \beta$-estradiol data were unavailable for one woman because of a technical failure $(n=15$ in analyses concerning menstrual phase related change in $17 \beta$-estradiol level and relationships between $17 \beta$-estradiol and startle measures).

The study employed a within-subjects design. Participants were tested, counterbalanced for menstrual cycle phase, twice: once during the follicular phase (days 1-7, starting from the first day of last menstruation) and once during the luteal phase (days 21-25).

The study was approved by the local research ethics committee. All participants provided written informed consent.

\section{PPI and PPF of the Startle Response}

Startle response measurement. Testing took place in a moderately lit soundproof laboratory. A commercial computerized human startle response monitoring system (Mark II, SR Lab, San Diego, California, USA) was used for the delivery of the acoustic startle stimuli and for the recording/scoring of the electromyographic (EMG) activity for $250 \mathrm{~ms}$ starting from the stimulus onset. Stimuli were presented binaurally through headphones (Telephonics, TDH 39P). The eyeblink component of the startle response was indexed by recording EMG activity of the orbicularis oculi muscle by positioning two miniature silver/silver chloride electrodes filled with Dracard electrolyte paste (SLE, Croydon) beneath the right eye. The ground electrode was attached to the mastoid behind the right ear. The EMG signal amplification gain control was kept constant for all participants and recorded EMG activity was band-pass filtered, as recommended by the SR-Lab. A $50-\mathrm{Hz}$ filter was used to eliminate the $50-\mathrm{Hz}$ interference. EMG data were scored off-line by the analytic program of this system for response amplitude and latency to response peak (in $\mathrm{ms}$ ). Latency to response onset was defined by a shift of 20 digital units from the baseline value occurring within $18-100 \mathrm{~ms}$ after the stimulus. The latency to response peak was determined as the point of maximal amplitude that occurred within $120 \mathrm{~ms}$ from the acoustic stimulus. If the onset and peak latencies differed by more than $95 \mathrm{~ms}$ or the baseline values shifted by more than 50 units then the responses were rejected ( $<5 \%$ trials).

Paradigm and procedure. The experimental paradigm was exactly the same as used in Kumari et al (2008). The pulsealone stimulus was a 40 -ms presentation of $115 \mathrm{~dB}$ (A) white noise and the prepulse stimulus was a $20-\mathrm{ms}$ presentation of $84 \mathrm{~dB}$ (A) noise, both presented over $70 \mathrm{~dB}$ (A) continuous background noise. The session began with a 5-min 
acclimatization period consisting of $70 \mathrm{~dB}$ (A) continuous white noise. Participants received 100 startle stimuli in all. An initial pulse-alone trial was followed by 99 trials, in three blocks of 33 trials each. There was a range of prepulseto-pulse intervals to elicit PPI (30, 60, 120, 240, and $480 \mathrm{~ms})$ and PPF $(1000,2000,3000,4500$, and $6000 \mathrm{~ms})$. Each block had three pulse-alone trials and three trials with each prepulse-pulse-to-pulse interval presented in a pseudorandom order (mean inter-trial-interval $=15 \mathrm{~s}$; range 9-23 s). The session lasted approximately $30 \mathrm{~min}$. Participants were instructed to keep their eyes open during the experiment and not given any specific instructions to either attend to or ignore the auditory stimuli.

\section{Hormonal Assessments}

One saliva sample was collected just before and one sample just after, the startle experiment, with two additional samples taken at 30 -min intervals to measure $17 \beta$-estradiol (chief estrogen), progesterone, and testosterone levels. Saliva steroid concentrations reflect the plasma free concentration, which is the biologically active fraction, and are similar to those observed in cerebrospinal fluid (Schwarz and Pohl, 1992). Saliva steroid levels correlate highly positively with blood steroid levels (Walker et al, 1984a, b; Vining 1986).

Participants were requested not to eat, drink, chew gum, or brush their teeth $30 \mathrm{~min}$ before sampling. Otherwise they had to rinse their mouth thoroughly with cold water $5 \mathrm{~min}$ prior to sample collection. The participants passed saliva (minimum of $2 \mathrm{ml}$ ) through a plastic straw into a $3-\mathrm{ml}$ polypropylene 'Cryovial' (Thermoscientific, Birmingham, UK). Following the manufacturer's recommendation, the samples were frozen at $-20^{\circ} \mathrm{C}$ and stored. Prior to analysis, saliva specimens collected at the four time points were defrosted, mixed and, after centrifugation at 3500 revolutions per minute (RPM) at room temperature, equal volumes were taken from each specimen to form a pooled specimen. Small aliquots $(50 \mu \mathrm{l})$ of these pooled specimens were separately analyzed (by AP) in duplicate, for estradiol, progesterone, and testosterone, by Luminescence immunoassay (IBL, Hamburg, Germany). If the difference between the duplicate measurements was more than $10 \%$, then the analysis was repeated. Briefly, using the Genesis 100 Robotic Sample Processor (Tecan UK, Theale, Reading, $\mathrm{UK}), 50 \mu \mathrm{l}$ of the test saliva or standard was added to the well of microtitration strips. This was followed by $50 \mu \mathrm{l}$ of a solution of the enzyme-labelled hormone and $50 \mu \mathrm{l}$ of the hormone antibody. After an incubation of $4 \mathrm{~h}$ at room temperature, the incubation solution was discarded and the wells were washed four times with $250 \mu \mathrm{l}$ of wash buffer and $50 \mu \mathrm{l}$ of chemiluminescence reagent added. The luminescence of the bound fraction was measured in a Berthold luminometer (MPL1, Berthold Detection Systems, Pforzheim, Germany), which was linked to MikroWin 2000 Version 4 (Microtek Laborsysteme, Ovoroth, Germany) for immunoassay data processing. Hormone concentrations were read off a calibration graph, constructed from a series of hormone standards. The day-to-day performance of the assays was monitored using each kit's saliva control specimens and also the commercial control sera (Immunoassay-plus, Biorad, Hemel Hempstead, Herts, UK), which had been suitably diluted with each kit's zero standard. For $17 \beta$-estradiol, the range of standards was from 0 to $64 \mathrm{pg} / \mathrm{ml}$ and the analytical sensitivity was $0.3 \mathrm{pg} / \mathrm{ml}$; intra-assay precision $(\mathrm{CV}):<10 \%$ at $10-40 \mathrm{pg} / \mathrm{ml}$; inter-assay precision ca. $12 \%$ at $33 \mathrm{pg} / \mathrm{ml}$. For progesterone, the range of standards was from 0 to $1000 \mathrm{pg} / \mathrm{ml}$ and the analytical sensitivity was $2.6 \mathrm{pg} / \mathrm{ml}$; intra-assay precision $(\mathrm{CV}):<10 \%$ at $10-100 \mathrm{pg} / \mathrm{ml}$; inter-assay precision $<10 \%$ at $20-800 \mathrm{pg} / \mathrm{ml}$. For testosterone, the range of standards was from 0 to $760 \mathrm{pg} / \mathrm{ml}$ and the analytical sensitivity was $1.8 \mathrm{pg} / \mathrm{ml}$; interand intra-assay precision (CV) $<10 \%$ at $20-540 \mathrm{pg} / \mathrm{ml}$ (http://www.ibl-hamburg.com/index,1.0.html; reference numbers RE62031 (Testosterone), RE62021 (Progesterone) and RE62041 (17 $\beta$-estradiol)).

\section{Statistical Analysis}

All analyses were carried out using Statistical Package for the Social Sciences (SPSS, version 15) with alpha level for significance testing maintained at $p \leqslant 0.05$ unless otherwise specified. All repeated measures with more than two levels employed the Greenhouse-Geisser epsilon $(\varepsilon)$ correction (uncorrected degrees of freedom are reported with the corrected $p$-values and the epsilon value).

\section{Startle Measures}

PPI and PPF were computed as percentage reduction of the amplitude over pulse-alone trials; PPI/PPF $=(\mathrm{a}-\mathrm{b}) / \mathrm{a} \times 100$, where ' $a$ ' $=$ amplitude over pulse-alone trials, and ' $\mathrm{b}$ ' $=$ amplitude over prepulse trials. The PPI data were analyzed separately to PPF (because PPF would be expressed as a negative value), following the approach used in previous investigations involving both PPI and PPF (eg, Hazlett et al, 1998; Kumari et al, 2004, 2008).

Menstrual phase-related variability in PPI was evaluated with a $2 \times 5$ (Menstrual Phase (follicular, luteal) $\times$ Trial Type (30, 60, 120, 240, and 480-ms prepulse trials)) repeated-measures analyses of variance (ANOVA) with Menstrual Phase and Trial Type as within-subject factors. Menstrual phase-related variability in PPF was evaluated, separate to PPI, with a $2 \times 5$ (Menstrual Phase $\times$ Trial Type $(1000,2000,3000,4500$, and $6000-\mathrm{ms}$ prepulse trials)) repeated-measures ANOVA.

The influence of Menstrual Phase on initial reactivity was examined using repeated-measures ANOVA on amplitude over the first pulse-alone trial. The effects of Menstrual Phase in the amplitude and habituation of the startle response over the entire session were evaluated by a $2 \times 3$ (Menstrual Phase $\times$ Block (three blocks of three pulsealone trails each)) repeated-measures ANOVA. The latencies to response peak were analyzed by $2 \times 6$ (Menstrual Cycle $\times$ Trial Type (pulse-alone and PPI/PPF trials)) repeated-measures ANOVA. We did not include Block as a further within-subjects variable when examining Menstrual Phase effects in PPI and PPF because of missing values (no measurable startle responses) in three luteal or follicular participants during one or other PPI/PPF condition in the second or third block (one follicular participant, 60-ms prepulse condition in block 2; one luteal participant, 480-ms condition in block 3; one follicular participant, 1000-ms condition in block 3). We, however, confirmed the 
effects of menstrual cycle phase in PPI and PPF observed over the entire session with further analyses restricted to the first block of trials. The order of menstrual phase (luteal first, follicular first) was initially included as a betweensubjects factor in all the analyses described above but then excluded as it had no significant main or interaction effects in any of the measures.

\section{Cyclic Fluctuations in Sex Hormones and Their Relationships to PPI and PPF}

The changes in $17 \beta$-estradiol, progesterone, and testosterone levels as a function of menstrual cycle phase were analyzed (separately) using one-way repeated-measures ANOVAs. Correlational analyses (Pearson's r) examined the relationships between (a) hormonal levels and PPI and PPF, separately at the two menstrual phases, and (b) changes in hormonal levels and changes in PPI and PPF from the follicular to the luteal phase. To restrict the number of correlations performed, only 120 -ms PPI and 4500-ms PPF scores were examined as these were the most effective intervals.

\section{RESULTS}

\section{Startle Measures}

Prepulse inhibition. The $2 \times 5$ MANOVA revealed a marginally significant main effect of Menstrual Phase $(F(1,16)=$ $4.51, p=0.05)$ indicating more PPI during the follicular than during the luteal phase, and a significant main effect of Trial Type $(\mathrm{F}(4,60)=3.59$, corrected $p=0.035, \varepsilon=0.55)$ showing, as in previous studies, more PPI on $120 \mathrm{~ms}$ than on $30 \mathrm{~ms}$ and $480 \mathrm{~ms}$ prepulse trials (Figure 1). Menstrual cycle phase $\times$ Trial Type interaction was not significant $(\mathrm{F}(4,60)=$ 0.56 , corrected $p=0.60, \varepsilon=0.71$ ).

The analysis of the first block of trials revealed a strong trend for the main effect of Menstrual Phase $(F(1,16)=4.00$, $p=0.06$ ) indicating more PPI during the follicular than during the luteal phase, a significant main effect of Trial Type (F $(4,60)=7.08$, corrected $p=0.001, \varepsilon=0.94$; effects as described above for the entire session), as well as a significant Menstrual Phase $\times$ Trial Type interaction $(\mathrm{F}(4,60)=3.01$, corrected $p=0.035, \varepsilon=1.00$ ). The analysis of Menstrual Phase $\times$ Trial Type interaction revealed significantly lower PPI during the luteal compared with the follicular phase with $60 \mathrm{~ms}(\mathrm{t}(16)=2.72, p=0.016)$ and 120 -ms prepulse trials ( $\mathrm{t}(16)=2.85, p=0.012)$; there was less marked and nonsignificant reduction with other trial types $(30 \mathrm{~ms}$ : t $(16)=1.61, p=0.13 ; 240 \mathrm{~ms}: \mathrm{t} \quad(16)=0.71, p=0.49$; $480 \mathrm{~ms}: \mathrm{t}(16)=0.62, p=0.54)$.

Prepulse facilitation. There was only a significant main effect of Menstrual Phase $(\mathrm{F}(1,16)=4.97, p=0.04)$ showing less PPF across trials during the follicular than the luteal phase (Figure 1). The main effect of Trial Type was not significant $(\mathrm{F}(4,60)=1.15$, corrected $p=0.33, \varepsilon=0.61)$. Menstrual cycle phase $\times$ Trial Type interaction was also not significant $(\mathrm{F}(4,60)=0.60$, corrected $p=0.67, \varepsilon=0.77)$.

The analysis of the first block of trials revealed a marginally significant main effect of Menstrual Phase $(\mathrm{F}(1,16)=4.36, p=0.05)$ indicating less PPF during the follicular than during the luteal phase, and a significant main effect of Trial Type $(\mathrm{F}(4,60)=3.21$, corrected $p=0.04$, $\varepsilon=0.77)$ showing more PPF on $4500 \mathrm{~ms}$ than on $1000-\mathrm{ms}$ prepulse trials (Figure 1). Menstrual Phase $\times$ Trial Type interaction was not significant $(F(4,60)=0.80$, corrected $p=0.53, \varepsilon=0.72$ ).

\section{Initial Startle Reactivity, Response Amplitude, and Habituation}

Menstrual Phase had no effect in initial startle reactivity $(\mathrm{F}=0.75)$ (Table 1$)$. There was strong habituation during both menstrual phases over three blocks of pulse-alone

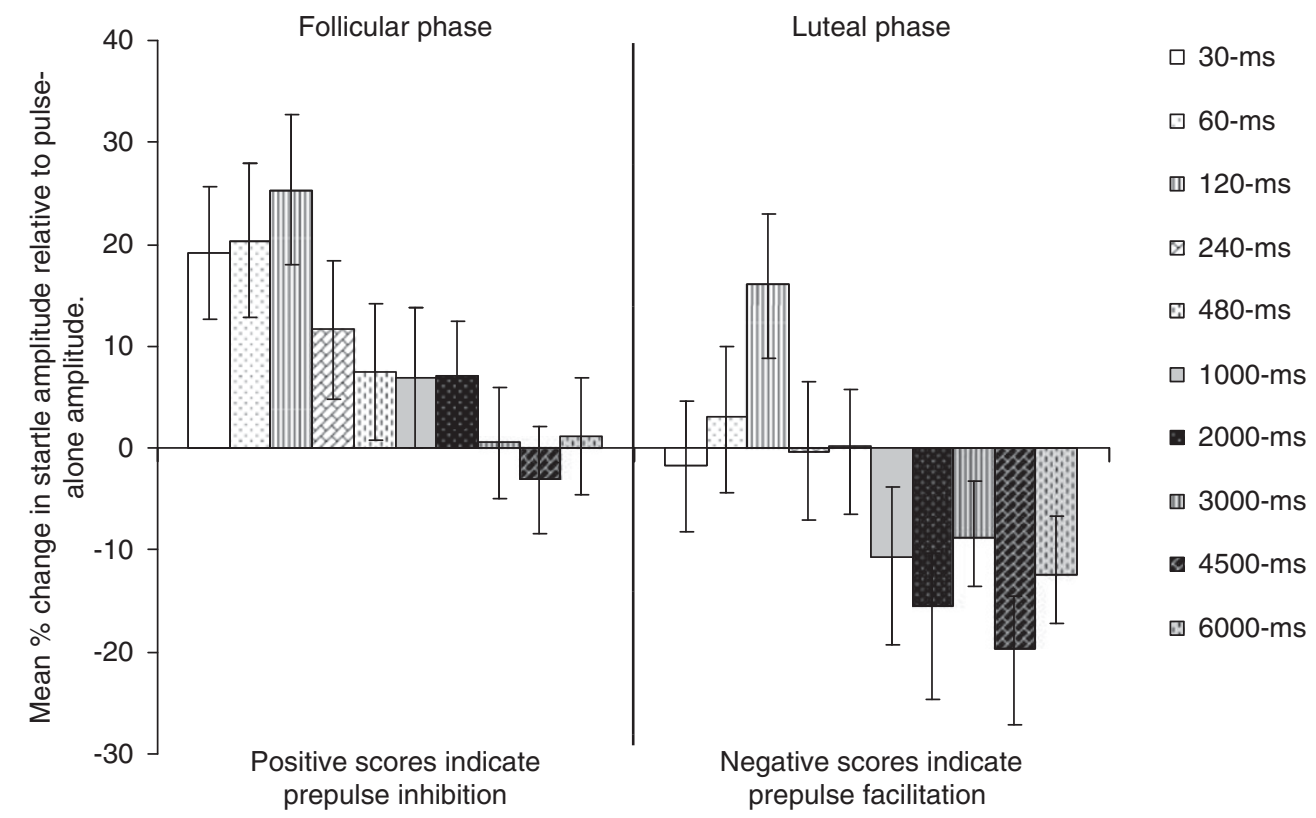

Figure I Mean startle modulation with a range of prepulse-to-pulse intervals during the follicular and luteal phases. Error bars show \pm I SEM. 
Table I Mean (SEM) Amplitudes (Analogue-to-Digit Units) Over Pulse-Alone Trials, and Latencies to Response Peak (ms) for PulseAlone Trials, PPI, and PPF Trials During the Follicular and Luteal Phases

\begin{tabular}{|c|c|c|}
\hline Measure & $\begin{array}{c}\text { Follicular phase } \\
\text { mean (SEM) }\end{array}$ & $\begin{array}{l}\text { Luteal phase } \\
\text { mean (SEM) }\end{array}$ \\
\hline \multicolumn{3}{|l|}{ Amplitude } \\
\hline First pulse-alone trial (initial reactivity) & $670.06(120.45)$ & $755.87(\mid 18.17)$ \\
\hline \multicolumn{3}{|l|}{ Blocks: each of 3 pulse-alone trials } \\
\hline Block I & $564.20(107.78)$ & $626.20(1 \mid 8.76)$ \\
\hline Block 2 & $472.38(119.04)$ & 471.01 (87.43) \\
\hline Block 3 & $487.83(127.94)$ & $462.94(97.19)$ \\
\hline \multicolumn{3}{|c|}{ Latencies to response peak for pulse-alone, PPI, and PPF trials } \\
\hline Pulse-alone & $57.86(2.13)$ & $60.93(1.60)$ \\
\hline \multicolumn{3}{|l|}{ PPI } \\
\hline 30 ms prepulse-to-pulse interval & $55.57(1.75)$ & $58.33(2.09)$ \\
\hline 60 ms prepulse-to-pulse interval & $55.99(3.17)$ & $54.88(1.96)$ \\
\hline I 20 ms prepulse-to-pulse interval & $57.41(2.56)$ & $62.59(3.07)$ \\
\hline 240 ms prepulse-to-pulse interval & $59.21(3.95)$ & $63.47(3.84)$ \\
\hline 480 ms prepulse-to-pulse interval & $58.99(3.29)$ & $61.03(3.54)$ \\
\hline \multicolumn{3}{|l|}{ PPF } \\
\hline I000 ms prepulse-to-pulse interval & $58.54(2.73)$ & $61.27(2.15)$ \\
\hline 2000 ms prepulse-to-pulse interval & $56.97(2.77)$ & $57.34(1.75)$ \\
\hline 3000 ms prepulse-to-pulse interval & $56.46(1.47)$ & $62.18(2.04)$ \\
\hline 4500 ms prepulse-to-pulse interval & $59.98(2.48)$ & $60.72(1.81)$ \\
\hline 6000 ms prepulse-to-pulse interval & $60.11(1.87)$ & $59.09(1.68)$ \\
\hline
\end{tabular}

trials (Block, $\mathrm{F}(2,30)=8.46, p=0.002 ; \varepsilon=0.84$; linear $\mathrm{F}$ $(1,15)=17.96, \quad p=0.001) \quad($ see Table 1 mean values). Menstrual Phase and Menstrual Phase $\times$ Block effects were not significant $(\mathrm{F}<1)$.

\section{Latencies to Response Peak}

Prepulse inhibition. There was only a trend for main effect of Trial Type $(\mathrm{F}(5,75)=2.45$, corrected $p=0.06, \varepsilon=0.71)$ (see Table 1 mean values).

Prepulse facilitation. Menstrual Phase and Trial Type had no main or interactive effects $(\mathrm{F}<2)$ in this measure (see Table 1 mean values).

\section{Cyclic Fluctuations in Sex Hormones and Their Relationships to PPI and PPF}

$17 \beta$-Estradiol. The main effect of Menstrual Phase (F $(1,14)$ $=5.88, p=0.03 ; n=15$, data unavailable for one woman) indicated a higher level, on average, during the luteal phase, compared with the follicular phase (Table 2). The $17 \beta$-estradiol levels did not correlate significantly with PPI or PPF during the follicular or the luteal phase (Table 3 ). The changes from the follicular to the luteal phase in $17 \beta$-estradiol and PPI/PPF levels were also not directly correlated (Table 3).
Table 2 Hormone Levels During the Follicular and Luteal Phases

\begin{tabular}{lcc}
\hline Hormones & $\begin{array}{c}\text { Follicular phase } \\
\text { mean (SD) }\end{array}$ & $\begin{array}{c}\text { Luteal phase } \\
\text { mean (SD) }\end{array}$ \\
\hline $17 \beta$-estradiol $(\mathrm{pg} / \mathrm{ml})^{\mathrm{a}}$ & $5.56(4.84)$ & $9.75(9.58)$ \\
Progesterone $(\mathrm{pg} / \mathrm{ml})$ & $53.00(32.43)$ & $147.55(72.96)$ \\
Testosterone $(\mathrm{pg} / \mathrm{ml})^{\mathrm{a}}$ & $26.32(14.92)$ & $31.27(33.01)$
\end{tabular}

${ }^{\mathrm{a}} N=15$; data unavailable for one woman because of a technical failure.

Table 3 Pearson's Correlations Between Hormones and PPI/PPF Levels

\begin{tabular}{|c|c|c|c|}
\hline Measure & $\begin{array}{c}\text { Menstrual } \\
\text { phase }\end{array}$ & $\mid 7 \beta$-estradiol $\left.\right|^{a}$ & a Progesterone \\
\hline \multirow[t]{2}{*}{ PPI $120 \mathrm{~ms}$} & Follicular & 0.093 & 0.269 \\
\hline & Luteal & -0.317 & 0.478 \\
\hline \multirow[t]{2}{*}{ PPF $4500 \mathrm{~ms}$} & Follicular & -0.154 & -0.159 \\
\hline & Luteal & 0.152 & -0.024 \\
\hline
\end{tabular}

\begin{tabular}{|c|c|c|}
\hline \multirow[t]{2}{*}{$\begin{array}{l}\text { Correlations between changes from } \\
\text { the follicular to luteal phase }\end{array}$} & \multicolumn{2}{|c|}{$\begin{array}{l}\text { Increase from follicular to } \\
\text { luteal phase in hormones }\end{array}$} \\
\hline & I $7 \beta$-estradiol & Progesterone \\
\hline $\begin{array}{l}\text { PPI } 120 \text { ms: decrease from follicular } \\
\text { to luteal phase }\end{array}$ & 0.010 & $-0.521 *\left(0.650^{\mathrm{b} * *}\right)$ \\
\hline $\begin{array}{l}\text { PPF } 4500 \text { ms: increase from follicular } \\
\text { to luteal phase }\end{array}$ & 0.002 & 0.158 \\
\hline
\end{tabular}

Progesterone. There was a strong main effect of Menstrual Phase $(\mathrm{F}(1,15)=26.60, p<0.001)$ revealing a higher level, on average, during the luteal phase, compared with the follicular phase (Table 2). A larger increase in progesterone level was associated with a smaller decrease in PPI from the follicular to the luteal phase (Table 3).

Testosterone. Testosterone level was not significantly affected by the Menstrual Phase $(\mathrm{F}=0.57)$ and (Table 2) and showed no significant association with PPI or PPF either during the follicular or the luteal phase.

\section{DISCUSSION}

The findings confirmed our hypothesis of reduced PPI during the luteal phase, compared with the follicular phase, in healthy young women. We also found an increase in PPF from the follicular to the luteal phase. The amplitude and habituation of the startle amplitude were not different between the two phases. We did not find support for our hypothesis of a direct correlation between changes in PPI/ PPF and estrogen levels. A greater increase in progesterone was associated with a smaller reduction in PPI from the follicular to the luteal phase. 
The finding showing less PPI during the luteal phase, compared with the follicular phase, is consistent with earlier published data on this topic (Swerdlow et al, 1997; Jovanovic et al, 2004). This study also revealed less PPI but more PPF during the luteal phase and vice versa for the follicular phase. We earlier suggested that 'gender differences in human sensorimotor gating might represent a general downshift in the inhibition curve and upward shift in the facilitation curve in women compared with men' (Kumari et al, 2003). The findings of this study suggest that less PPI/more PPF pattern in young healthy women, relative to young healthy men, may be even more pronounced when women are in the luteal phase of their menstrual cycle. The pattern of observed effects may also differentiate healthy women (generally associated with low PPI compared with healthy men) from patients with schizophrenia. Schizophrenia is associated (where examined) with reductions in both PPI and PPF (reviewed in Kumari et al, 2004) whereas cyclic fluctuations in ovarian hormones appear to change PPI and PPF in opposite directions in healthy women. There may be an evolutionary significance of changes in information processing profiles of young women over the menstrual cycle.

Progesterone is considered to possess psychotropic properties in addition to its role in reproductive endocrinology (Rupprecht, 2003). The finding showing a beneficial effect of progesterone at the luteal phase (ie, less reduction in PPI) may be akin to the reversal of apomorphine-induced disruption of PPI by progesterone in the rat observed by Rupprecht et al (1999). Rupprecht et al (1999) also showed the reversal of apomorphine-induced disruption of PPI by haloperidol and suggested that progesterone has 'atypical antipsychotic-like effect' because, unlike haloperidol, it did not induce catalepsy and did not antagonize amphetamineinduced stereotypy. This may be related to the involvement of progesterone in multiple receptor systems. Progesterone is known to modulate the release of dopamine (Dluzen and Ramirez, 1990; Ramirez and Zheng, 1996), to act as a functional antagonist at 5-HT3 receptors (Wetzel et al, 1998), as well as to play a role in the control of nicotinic cholinergic receptors (Valera et al, 1992). Given the known sensitivity of PPI to dopaminergic, serotonergic, glutamatergic, and cholinergic systems (Swerdlow and Geyer, 1998; Geyer et al, 2001), the data available so far do not allow us to speculate, which of these systems might be most pertinent to the effects of progesterone in PPI of healthy young women. Nonetheless, the present finding can be taken to suggest differential effects of progesterone and estrogen, or at least their complex interactive effects, in menstrual cycle-related variability in PPI/PPF.

In animal studies, different patterns of changes in cognitive performance are reported when rodents are treated with each steroid alone or co-administered, and the effects are dependent on the age, dosing regimen, and task characteristics (for reviews, see Rupprecht, 2003; Daniel, 2006; Pluchino et al, 2009). Progesterone is reported to enhance cognitive performance, independent of estrogen, in young adult rodents (Frye and Lacey, 2000) and to enhance performance of aged mice on tasks mediated by the prefrontal cortex and the hippocampus but not on those medicated primarily by the amygdala, striatum and the cerebellum (Frye and Walf, 2008). There is also previous evidence of better performance on prefrontal lobe-based cognitive tasks in healthy young women during the high progesterone early luteal phase (Solis-Ortiz et al, 2004). More recently, Solís-Ortiz and Corsi-Cabrera (2008) have shown increased sustained attention by progesterone during the early luteal phase and increased visual spatial memory by estrogens during the ovulatory phase in healthy young women. A high level of progesterone in our study was associated significantly with a lower decrease in PPI from the follicular to the luteal phase (and nonsignificantly with an increased in PPF which, as noted in the Introduction section, is considered to reflect sustained attention). Recent neuropsychological studies have suggested susceptibility of PPI to cognitive processes controlled in a 'top-down' manner by the frontal cortex and shown that greater PPI in healthy people covaries with superior performance on tasks that rely on the integrity and efficiency of frontal lobe function (Bitsios and Giakoumaki, 2005; Bitsios et al, 2006; Giakoumaki et al, 2006). Given these data and the presence of progesterone receptors in the frontal cortex (Blaustein, 2003), the beneficial effect of progesterone in PPI is may be mediated, at least in part, via frontal lobes. Attention to the prepulses, especially at long lead intervals $(>100 \mathrm{~ms}$ ), produces an increase in PPI (Dawson et al, 1997) so it possible that progesterone-related increase in attention served to offset some disruption of PPI during the (high estrogen) luteal phase.

Considering possible restoration by progesterone of luteal phase PPI disruption in this study within the context of schizophrenia, women are more susceptible to the onset of schizophrenia after menopause and during the post-partum period (Häfner $e t a l, 1993$ ). This effect can be attributed to a drop in progesterone level (Shulman and Tibbo, 2005). Studies have also reported high progesterone levels in unmedicated chronic patients in response to metabolic stress (Breier and Buchanan, 1992) but normal progesterone levels in medicated early psychosis (Oades and Schepker, 1994) as well medicated chronic schizophrenia patients (Taherianfard and Shariaty, 2004). Progesterone has been suggested to act as an endogenous antipsychotic and serve to restore normal functions during the times of stress (Shulman and Tibbo, 2005). Further support for this notion comes from the reports that progesterone metabolite $3 \alpha$, $5 \alpha$-THP produces a behavioral profile similar to that of dopamine receptor antagonists by increasing GABAergic tone in rodents (Motzo et al, 1996; Khisti et al, 1998, 2002). Other data in rodents show increases in cortical progesterone and/or $3 \alpha, 5 \alpha$-THP concentrations with olanzapine (Marx et al, 2000, 2003) and clozapine (Barbaccia et al, 2001; Marx et al, 2003), but not with haloperidol (Barbaccia et al, 2001). It is possible that antipsychotics-induced increases in progesterone contribute to the clinical effects of these drugs (Barbaccia, 2004; Marx et al, 2006).

This study failed to find a direct association between changes in estrogen and PPI levels. It is possible that reduction in PPI at the luteal phase is not fully explained by changes in estrogen and also includes the influence of hormones, such as oxytocin. Oxytocin varies across the menstrual cycle in non-pill user healthy young women (lower during the luteal phase compared with the follicular and ovulatory phases; eg, Salonia et al, 2005), and shown recently to have influence in PPI, via glutamatergic 
component, in experimental animals (Caldwell et al, 2009). This study may also be limited by relatively smaller fluctuations in estrogen, relative to progesterone. However, saliva $17 \beta$-estradiol and progesterone concentrations obtained in this study are within the normal range quoted by the manufacturer of the kit (IBL Immunono-Biological Laboratory, 2009). Our data are also in agreement with those of a number of other studies, which observed 3-8 times higher salivary progesterone levels during the luteal phase, relative to the follicular phase (Walker et al, 1984a; Lipson and Ellison 1996; Gandara et al, 2007), and relatively smaller changes in salivary estrogen levels between the two menstrual phases (Walker et al, 1984a; Read 1993; Chatterton et al, 2005). Further studies with data collection over more than two time points during the menstrual cycle and relatively larger samples are required to confirm and extend the present findings.

In conclusion, this study observed more PPI during the follicular phase and more PPF during the luteal phase with comparable level of startle amplitude and habituation during the two phases. A larger increase in progesterone level was associated with a smaller decrease in PPI from the follicular to the luteal phase. No direct significant association occurred between changes in PPI and estrogen levels. The findings confirm previous reports of lower PPI during the luteal compared with the follicular phase, and suggest a role for progesterone, more specifically an antipsychoticlike action of progesterone during the (high estrogen) luteal phase in PPI of healthy young women.

\section{ACKNOWLEDGEMENTS}

The study was funded by a grant (SG-39919; to VK and AC) from the British Academy, UK. We are grateful to Mrs Irene Papadopoulos for her help with the study.

\section{DISCLOSURE}

The authors declare no conflict of interest.

\section{REFERENCES}

Aasen A, Kolli L, Kumari V (2005). Sex effects in prepulse inhibition and facilitation of the acoustic startle response: implications for pharmacological and treatment studies. J Psychopharmacol 19: 39-45.

Abel K, Waikar M, Pedro B, Hemsley D, Geyer M (1998). Repeated testing of prepulse inhibition and habituation of the startle reflex: a study in healthy human controls. J Psychopharmacol 12: 330-337.

Anthony BJ (1985). In the blink of an eye: implications of reflex modification for information processing. In: Ackles PK, Jenings JR, Coles MGH (eds). Advances in Psychophysiology Vol. 1 JAI Press: Greenwich, CT. pp 167-218.

Barbaccia ML (2004). Neurosteroidogenesis: relevance to neurosteroid actions in brain and modulation by psychotropic drugs. Crit Rev Neurobiol 16: 67-74.

Barbaccia ML, Affricano D, Purdy RH, Maciocco E, Spiga F, Biggio G (2001). Clozapine, but not haloperidol, increases brain concentrations of neuroactive steroids in the rat. Neuropsychopharmacol 25: 489-497.
Bitsios P, Giakoumaki SG (2005). Relationship of prepulse inhibition of the startle reflex to attentional and executive mechanisms in man. Int J Psychophysiol 55: 229-241.

Bitsios P, Giakoumaki SG, Theou K, Frangou S (2006). Increased prepulse inhibition of the acoustic startle response is associated with better strategy formation and execution times in healthy males. Neuropsychologia 44: 2494-2499.

Blaustein JD (2003). Progestin receptors: neuronal integrators of hormonal and environmental stimulation. Ann NY Acad Sci 1007: 238-250.

Braff DL, Geyer MA (1990). Sensorimotor gating and schizophrenia. Arch Gen Psychiatry 47: 181-188.

Braff DL, Geyer MA, Swerdlow NR (2001). Human studies of prepulse inhibition of startle: normal subjects, patient groups, and pharmacological studies. Psychopharmacology 156: 234-258.

Braff DL, Stone C, Callaway E, Geyer M, Glick I, Bali L (1978). Prestimulus effects on human startle reflex in normals and schizophrenics. Psychophysiology 15: 339-343.

Breier A, Buchanan RW (1992). The effects of metabolic stress on plasma progesterone in healthy volunteers and schizophrenic patients. Life Sci 51: 1527-1534.

Caldwell HK, Stephens SL, Young III WS (2009). Oxytocin as a natural antipsychotic: a study using oxytocin knockout mice. Mol Psychiatry 14: 190-196.

Castle DJ, Murray RM (1991). The neurodevelopmental basis of sex differences in schizophrenia. Psychol Med 21: 565-575.

Castle DJ, Abel K, Takei N, Murray RM (1995). Gender differences in schizophrenia: hormonal effect or subtypes? Schizophr Bull 21: $1-12$.

Chatterton Jr RT, Mateo ET, Hou N, Rademaker AW, Acharya S, Jordan VC et al (2005). Characteristics of salivary profiles of oestradiol and progesterone in premenopausal women. $J$ Endocrinol 186: 77-84.

Daniel JM (2006). Effects of oestrogen on cognition: what have we learned from basic research? J Neuroendocrinol 18: 787-795.

Dawson ME, Schell AM, Swerdlow NE, Filion DL (1997). Cognitive, clinical, and neuropsychological implications of startle modulation. In: Lang PJ, Simons RF, Balaban M, Mahwah NJ (eds). Attention and Orienting: Sensory and Motivational Processes. Lawrence Erlbaum Associates: Mahwah, NJ. pp 257-279.

Dluzen DE, Ramirez VD (1990). In vitro progesterone modulates amphetamine-stimulated dopamine release from the corpus striatum of castrated male rats treated with estrogen. Neuroendocrinology 2: 517-520.

Faraday MM, O’Donoghue VA, Grunberg NE (1999). Effects of nicotine and stress on startle amplitude and sensory gating depend on rat strain and sex. Pharmacol Biochem Behav 62: 273-284.

Faraone SV, Chen WJ, Goldstein JM, Tsuang MT (1994). Gender differences in age at onset of schizophrenia. Br J Psychiatry 164: 625-629.

Frye CA, Lacey EH (2000). Progestins influence performance on cognitive tasks independent of changes in affective behaviour. Psychobiology 28: 550-563.

Frye CA, Walf AA (2008). Progesterone enhances performance of aged mice in cortical or hippocampal tasks. Neurosci Lett 437: $116-120$.

Gandara BK, Leresche L, Mancl L (2007). Patterns of salivary estradiol and progesterone across the menstrual cycle. Ann NY Acad Sci 1098: 446-450.

Geyer MA, Krebs-Thomson K, Braff DL, Swerdlow NR (2001). Pharmacological studies of prepulse inhibition models of sensorimotor gating deficits in schizophrenia: a decade in review. Psychopharmacology 156: 117-154.

Giakoumaki SG, Bitsios P, Frangou S (2006). The level of prepulse inhibition in healthy individuals may index cortical modulation of early information processing. Brain Res 1078: 168-170. 
Gogos A, Van den Buuse M (2004). Estrogen and progesterone prevent disruption of prepulse inhibition by the serotonin-1A receptor agonist 8-hydroxy-2-dipropylaminotetralin. J Pharmacol Exp Ther 309: 267-274.

Graham FK (1975). The more or less startling effects of weak prestimuli. Psychophysiol 12: 238-248.

Graham FK, Murray GM (1977). Discordant effects of weak prestimulation on magnitude and latency of the blink reflex. Physiol Psychol 5: 108-114.

Häfner H, Riecher-Rössler A, An Der Heiden W, Maurer K, Fätkenheuer B, Löffler W (1993). Generating and testing a causal explanation of the gender difference in age at first onset of schizophrenia. Psychol Med 23: 925-940.

Häfner H, an der Heiden W, Behrens S, Gattaz WF, Hambrecht M, Löffler W et al (1998). Causes and consequences of the gender difference in age at onset of schizophrenia. Schizophr Bull 24: 99-113.

Hazlett EA, Buchsbaum MS, Haznedar MM, Singer MB, Germans MK, Schnur DB et al (1998). Prefrontal cortex glucose metabolism and startle eyeblink modification abnormalities in unmedicated schizophrenia patients. Psychophysiol 35: 186-198.

Hoffman HS, Searle JL (1968). Acoustic and temporal factors in the evocation of startle. J Acoust Soc Am 43: 269-282.

IBL Immunono-Biological Laboratory. Saliva diagnostics: information leaflet. 2009. www.ibl-Hamburg.com.

Ison JR, Allen PD (2007). Pre- but not post-menopausal female $\mathrm{CBA} / \mathrm{CaJ}$ mice show less prepulse inhibition than male mice of the same age. Behav Brain Res 185: 76-81.

Jovanovic T, Szilagyi S, Chakravorty S, Fiallos AM, Lewison BJ, Parwani A et al (2004). Menstrual cycle phase effects on prepulse inhibition of acoustic startle. Psychophysiology 41: 401-406.

Khisti RT, Deshpande LS, Chopde CT (2002). The neurosteroid 3 alpha-hydroxy-5 alpha-pregnan-20-one affects dopaminemediated behavior in rodents. Psychopharmacology 161: $120-128$

Khisti RT, Mandhane SN, Chopde CT (1998). The neurosteroid 3 alpha-hydroxy-5 alpha-pregnan-20-one induces catalepsy in mice. Neurosci Lett 251: 85-88.

Koch M (1998). Sensorimotor gating changes across the estrous cycle in female rats. Physiol Behav 64: 625-628.

Kulkarni J (2009). Oestrogen - a new treatment approach for schizophrenia? Med J Aust 190(Suppl 4): S37-S38.

Kumari V, Aasen I, Sharma T (2004). Sex effects in prepulse modification deficits in schizophrenia. Schizophr Res 69: 219-235.

Kumari V, Aasen I, Papadopoulos A, Bojang F, Poon L, Halari R et al (2008). A comparison of prepulse inhibition in pre- and postmenopausal women and age-matched men. Neuropsychopharmacol 33: 2610-2618.

Kumari V, Gray J, Gupta P, Luscher S, Sharma T (2003). Sex differences in prepulse inhibition of the acoustic startle response. Pers Indiv Diff 34: 733-742.

Lipson SF, Ellison PT (1996). Comparison of salivary steroid profiles in naturally occurring conception and non-conception cycles. Hum Reprod 11: 2090-2096.

Marshall JC (2001). Hormonal regulation of the menstrual cycle and mechanisms of ovulation. In: Leslie J, De Groot J, Jamenson L (eds). Endocrinology. W.B. Saunders Company: Phliladelphia. pp 2073-2085.

Marx CE, Duncan GE, Gilmore JH, Lieberman JA, Morrow AL (2000). Olanzapine increases allopregnanolone in the rat cerebral cortex. Biol Psychiatry 47: 1000-1104.

Marx CE, Shampine LJ, Duncan GE, VanDoren MJ, Grobin AC, Massing MW et al (2006). Clozapine markedly elevates pregnenolone in rat hippocampus, cerebral cortex, and serum: candidate mechanism for superior efficacy? Pharmacol Biochem Behav 84: 598-608.
Marx CE, VanDoren MJ, Duncan GE, Lieberman JA, Morrow AL (2003). Olanzapine and clozapine increase the GABAergic neuroactive steroid allopregnanolone in rodents. Neuropsychopharmacology 28: 1-13.

Motzo C, Porceddu L, Maira G, Flore G, Concas A, Dazzi L et al (1996). Inhibition of basal and stress-induced dopamine release in the cerebral cortex and nucleus accumbens of freely moving rats by the neurosteroid allopregnanolone. J Psychopharmacol 67: 2212-2214.

Oades RD, Schepker R (1994). Serum gonadal steroid hormones in young schizophrenic patients. Psychoneuroendocrinology 19: 373-385.

Pluchino N, Cubeddu A, Giannini A, Merlini S, Cela V, Angioni S et al (2009). Pogestogens and brain: an update. Maturitas 62: 349-355.

Ramirez VD, Zheng J (1996). Membrane sex-steroid receptors in the brain. Front Neuroendocrinol 7: 402-449.

Read GF (1993). Status report on measurement of salivary estrogens and androgens. Ann NY Acad Sci 694: 146-160.

Riecher-Rössler A, Häfner H, Stumbaum M, Maurer K, Schmidt R (1994). Can estradiol modulate schizophrenic symptomatology? Schizophr Bull 20: 203-214.

Rupprecht R, Koch M, Montkowski A, Lancel M, Faulhaber J, Harting J et al (1999). Assessment of neuroleptic-like properties of progesterone. Psychopharmacology 143: 29-38.

Rupprecht R (2003). Neuroactive steroids: mechanisms of action and neuropsychopharmacological properties. Psychoneuroendocrinology 28: 139-168.

Salonia A, Nappi RE, Pontillo M, Daverio R, Smeraldi A, Briganti A et al (2005). Menstrual cycle-related changes in plasma oxytocin are relevant to normal sexual function in healthy women. Horm Behav 47: 164-169.

Schwarz S, Pohl P (1992). Steroid hormones and steroid hormone binding globulins in cerebrospinal fluid studied in individuals with intact and with disturbed blood-cerebrospinal fluid barrier. Neuroendocrinology 55: 174-182.

Shulman Y, Tibbo PG (2005). Neuroactive steroids in schizophrenia. Can J Psychiatry 50: 695-702.

Solis-Ortiz S, Guevara MA, Corsi-Cabrera M (2004). Performance in a test demanding prefrontal functions is favored by early luteal phase progesterone: an electroencephalographic study. Psychoneuroendocrinology 29: 1047-1057.

Solís-Ortiz S, Corsi-Cabrera M (2008). Sustained attention is favored by progesterone during early luteal phase and visuospatial memory by estrogens during ovulatory phase in young women. Psychoneuroendocrinology 33: 989-998.

Swerdlow NR, Auerbach A, Monroe SM, Hartson H, Geyer MA, Braff DL (1993). Men are more inhibited than women by weak prepulses. Biol Psychiatry 34: 253-260.

Swerdlow NR, Geyer MA (1998). Using an animal model of deficient sensorimotor gating to study the pathophysiology and new treatments of schizophrenia. Schizophr Bull 24: 285-301.

Swerdlow NR, Geyer MA, Hartman PL, Sprock J, Auerbach PP, Cadenhead K (1999). Sex differences in sensorimotor gating of the human startle response: all smoke? Psychopharmacology 146: 228-232.

Swerdlow NR, Hartson H, Auerbach A (1997). Changes in sensorimotor inhibition across the menstrual cycle: implications for neuropsychiatric disorders. Biol Psychiatry 41: 452-460.

Swerdlow NR, Light GA, Cadenhead KS, Sprock J, Hsieh MH, Braff DL (2006). Startle gating deficits in a large cohort of patients with schizophrenia: relationship to medications, symptoms, neurocognition, and level of function. Arch Gen Psychiatry 63: 1325-1335.

Talledo JA, Sutherland Owens AN, Schortinghuis T, Swerdlow NR (2009). Amphetamine effects on startle gating in normal women and female rats. Psychopharmacology 204: 165-175. 
Taherianfard M, Shariaty M (2004). Evaluation of serum steroid hormones in schizophrenic patients. Indian J Med Sci 58: 3-9.

Valera S, Ballivet M, Bertrand D (1992). Progesterone modulates a neuronal nicotinic acetylcholine receptor. Proc Natl Acad Sci USA 89: 9949-9953.

Vining RF (1986). Hormones in saliva. CRC Crit Rev Clin Lab Sci 23: 95-146.

Walker RF, Read GR, Riad-Fahmy D, Griffiths K (1984a). The assessment of ovarian function by the radioimmunoaassay of oestradiol-17-beta in saliva. In: Read GF, Riad-Fahmy D, Walker
RF, Griffiths K (eds). Immunoassays of Steroids in Saliva. Alpha Omega Publishing: Cardiff, Wales. pp 155-162.

Walker RF, Walker S, Riad-Fahmy D (1984b). Salivary Progesterone as an index of luteal function. In: Read GF, Riad-Fahmy D, Walker RF, Griffiths K (eds). Immunoassays of Steroids in Saliva. Alpha Omega Publishing: Cardiff, Wales. pp 115-126.

Wetzel CH, Hermann B, Behl C, Pestel E, Rammes G, Zieglgänsberger W et al (1998). Functional antagonism of gonadal steroids at the 5-hydroxytryptamine type 3 receptor. Mol Endocrinol 12: 1441-1451. 